\title{
FRACTURE STRENGTH AND MARGINAL GAP OF RE-PRESSED IPS E.MAX PRESS CROWNS WITH DIFFERENT CONCENTRATIONS
}

\author{
Shereen Kotb Salem* and Mohamed Mostafa Shalaby**
}

\begin{abstract}
Objective: The aim of this study was to investigate the effect of repressing IPS e.max Press with different concentrations on the marginal gap and fracture strength of ceramic crowns.

Materials and methods: Twenty-five IPS e.max Press crowns were fabricated. They were divided into 5 groups ( 5 samples in each group) according to the Wt.\% of the new ceramic ingots to the repressed ceramic. Group I is $100 \%$ new ceramics. Group II is $75 \%$ new and $25 \%$ repressed ceramics. Group III is $50 \%$ new and $50 \%$ repressed ceramics. Group IV is $25 \%$ new and $75 \%$ repressed ceramics. Group V is $100 \%$ repressed ceramics.
\end{abstract}

Each crown was seated on the copper mold and the marginal gap was measured at 16 predetermined points using a computer connected stereomicroscope. For fracture strength test the crowns were luted using resin cement on epoxy dies and subjected to fracture strength test.

Results: Group 1 (100\% new) recorded the least marginal gap $(32.7 \mu \mathrm{m})$, while group $5(100 \%$ repressed) recorded the highest marginal gap $(120.91 \mu \mathrm{m})$. No statistical significant difference between marginal gap of the first three groups (100\% new, $75 \%$ new $+25 \%$ repressed, $50 \%$ new $+50 \%$ repressed). A statistically significant difference was recorded between these 3 tested groups and group 4 ( $25 \%$ new $+75 \%$ repressed). There was also a significant difference between group 4 and group 5 (100\% repressed). Fracture strength results showed that Group I (100\% new) recorded the highest fracture strength $(929.724 \mathrm{~N})$, while group III (50\% new) recorded the least fracture strength $(819.366 \mathrm{~N})$. A statistical significant difference was found between the first four groups and a siginficant difference between GroupV (100\% repressed) and Group I,II,III. While, there was no significant difference between Group IV and Group V.

Conclusions: It was found that various weight percentages of repressed ceramics affected the marginal gap and had a significant effect when it exceeded $50 \%$, although all tested groups were clinically accepted. Also, homogeneity of the ceramic structure had a positive effect on fracture strength, as the least fracture strength was recorded for the $50 \%$ new $+50 \%$ repressed ceramic group and it increased significantly as this relation increased towards either the new ingot ceramics or the repressed ceramic:

KEY WORDS: Ceramic, Fracture strength, IPS e.max Press, Marginal gap, Repress.

* Lecturer of Fixed Prosthodontics, Faculty of Dentistry, October 6 University.

** Lecturer of Fixed Prosthodontics, Faculty of Dentistry, Minia University. 


\section{INTRODUCTION}

The high demands for metal-free, life-like restorations with consistent \& long-standing results caused an outstanding evolution of dental all-ceramic systems as well as new processing techniques in the latest three decades. ${ }^{(1,2)}$

Dental ceramics used are primarily glass ceramics, densely sintered alumina and zirconia-based ceramics. Composition of glass ceramics and their micro-structural variances result in discrepancies in the ceramics' mechanical properties. These structural variations may be in the glass matrix or in the crystalline phase; volume percent, crystal size, dispersal and morphology. Hot pressing of dental ceramics compared to other techniques like sintering, has become a very common and simple technique. It enhances better marginal adaptation and crystalline distribution within the glassy matrix. Also, less shrinkage, porosity and surface flaws. ${ }^{(3-9)}$

IPS Empress was presented in 1991 as the first heat-pressed leucite reinforced glass ceramic in which leucite $\left(\mathrm{SiO}_{2}, \mathrm{Al}_{2} \mathrm{O}_{3}, 4 \mathrm{~K}_{2} \mathrm{O}\right)$ is the main crystalline phase. ${ }^{(10,11)}$ IPS Empress2 was introduced in 1998. It is a lithium disilicate-reinforced glassceramic $\left(\mathrm{Li}_{2} \mathrm{OS}_{2} \mathrm{SiO}_{2}\right)$. According to the producer scientific documentation, ${ }^{(12)}$ the main crystalline phase is needle like crystals forming about $60 \%$ of glass ceramic volume. It offers higher strength of about $350 \mathrm{MPa}$, extending its use to short span fixed partial dentures. In 2005, IPS e.max Press (Ivoclar Vivadent, Schaan, Lichtenstein) substituted IPS Empress 2 because of its improved mechanical properties and significantly higher translucency. ${ }^{(13-15)}$ Its microstructure contains $70 \%$ lithium disilicate crystals embedded in a glassy matrix. Crystals are acicular in morphology and measure 3- $6 \mathrm{~mm}$ in length.

IPS e.max Press ceramic material is available in the form of ingots in 2 sizes with different shades and translucencies. Selection depends on the requirements of each clinical case. It is more economical to press several restorations from 1 ingot at the same time. Eventually, this is not usually possible and may result in a considerable amount of ceramic leftover represented by the removed button and sprue portions. The issue is thereby raised whether the leftover material should be discarded or reused. For financial reasons, some dental laboratories find these residual materials (pressed ceramics) useful for re-pressing. Also recycling in general is friendly to the environment. ${ }^{(2,16,17)}$ Scientific documentation about safety of reusing this residual ceramic is still insufficient.

Concerns as to the mechanical properties of the reused material for clinical use are valid. Although only few studies evaluated the re-pressed glass-ceramics, yet controversies were found, and researchers were divided into two groups: with and against the idea. ${ }^{(2,17)}$

These few studies mostly studied the flexure strength, translucency, colour, microstructure and X-ray diffraction (XRD) on ceramic discs. None were found to study other mechanical properties or properties related to clinical performance of the restoration; as marginal gap and fracture strength of a restoration already made of repressed ceramic.

Long-term clinical success of a dental restoration is influenced not only by mechanical, aesthetic, and biological properties, but also by marginal fit. Large marginal gap causes restoration failure due to quick dental cement dissolution and plaque accumulation, leading to marginal leakage then secondary caries. $(18,19)$ Dental restorations' marginal fit has been proven to be the key factor for secondary caries and periodontal diseases initiation which finally leads to restoration failure. ${ }^{(20-24)}$

Fracture from the engineering point of view is defined as, "rupture of a material too weak to sustain the forces on it". ${ }^{(25,26)}$ The strength of a material depends on the strength of the bond between its atoms. Most of materials fail to exhibit the predicted strength due to different factors. ${ }^{(27)}$ 
The thought that this ceramic leftover may not be enough for the pressing of a new restoration and may need to be mixed with new ceramic ingot, directs towards studying the mix ratio as well as microstructural and mechanical properties.

The aim of this study is to investigate the effect of repressing IPS e.max Press with different concentrations on the marginal gap and fracture strength of ceramic crowns. The hypothesis is that ceramic repressing will affect the fracture strength and marginal gap, and that mixing percentages may improve the results.

\section{MATERIALS AND METHODS}

\section{Factorial Design}

In this study, twenty-five IPS e.max Press crowns were fabricated. These crowns were divided into 5 groups (5 samples in each group) according to the $\mathrm{Wt} . \%$ of the new ceramic ingots to the repressed ceramic. Group I is $100 \%$ new ceramics. Group II is $75 \%$ new and $25 \%$ repressed ceramics. Group III is $50 \%$ new and $50 \%$ repressed ceramics. Group IV is $25 \%$ new and $75 \%$ repressed ceramics. Group $\mathrm{V}$ is $100 \%$ repressed ceramics.

\section{Samples constructions}

A copper die was constructed using an industrial lathe machine (CS 6240 Engine Bench lathe machine, China), to standardize the preparation of an upper premolar that will receive a ceramic crown. It has $1.0 \mathrm{~mm}$ heavy chamfer finish line according to manufacturer recommendations for the ceramic used. The die is $6^{\circ}$ taper from base to top. The occlusal surface has a notch to ensure precise crowns seating on the die.

Duplication of the copper die was done five times using duplicate material (REPLISIL $22 \mathrm{~N}$, dent-e-con e.K., Gartenstraße 19, Germany). Each duplicate was poured five times with epoxy resin (Kemapoxy 150, CMB International. Egypt).
For scanning, the metal die was sprayed with the scan powder to reduce reflections to be detected by the scanner (Identica hybrid, Medit Company, Seongbbuk-gu, Seol, Korea).

Using a CAD software (Exocad 2019 software) (Exocad Dental, Darmstadt, Germany), single crown resin pattern was designed, with flat axial surfaces with thickness ranged from $1 \mathrm{~mm}$ to $1.4 \mathrm{~mm}$ from finish line to the upper surface, respectively. The occlusal surface was designed to be $1.5 \mathrm{~mm}$ thick. The obtained STL file was sent to DentCase 3D printer (Mogassam, Egypt). The 25 resin patterns were printed using NextDent Cast (VertexDental B.V., Soesterberg, Netherlands), which is a monomer based on acrylic esters for manufacturing of 3D-printed castable parts, cured by direct light projection (DLP). The resin patterns were sprued then weighed using a sensitive digital scale (Sartorius Biopharmaceutical and Laboratories, Germany).

The resin patterns were invested using a specific type of phosphate-bonded investment IPS Press Vest Premium (Ivoclar Vivadent, Schaan, Lichtenstein). Invested patterns were preheated gradually for an hour in the burn-out furnace. Then they were immediately placed in the pressing furnace Programat EP3010 (Ivoclar Vivadent, Schaan, Lichtenstein). The ceramic ingots were plasticized at $920^{\circ} \mathrm{C}$, then pressed under vacuum. After pressing, the pressed crowns and the sprues were weighed, then the sprues were cut and the connection sites were smoothened. Ceramic crowns were glazed using IPS Ivocolor glaze (Ivoclar Vivadent, Schaan, Lichtenstein) at $735^{\circ} \mathrm{C}$. in furnace Programat P300 (Ivoclar Vivadent, Schaan, Lichtenstein).

The weight of the IPS e.max Press crowns were 2.3 times the resin patterns' weight. Weight needed for the IPS e.max Press crowns fabrication was calculated. The ceramic that will be repressed was ground to fit in the opening at the top surface of the investment mold. Ceramic material was placed in each pressing cycle according to the desired Wt.\%. 


\section{Marginal gap test}

Each crown was seated on the copper mold. The assembly was secured using a specially designed holding device. Marginal gap between the die and the crowns was measured at 16 predetermined points (28) using a computer connected stereomicroscope Leica MZ6 (Leica Microsystems, Switzerland) at magnification of 32x. using Leica Application Suite version 3.4 (Leica Microsystems, Switzerland)

\section{Cementation of the crowns}

Ceramic crowns were etched using IPS ceramic etching gel (Ivoclar Vivad ent, Schaan, Lichtenstein) $5 \%$ hydrofluoric acid Ceramic etchant for 20 seconds, as recommended by the manufacturer. Then the crowns were copiously washed with water/air spray. A layer of silane coupling agent Monobond-S (Ivoclar Vivadent, Schaan, Lichtenstein) was applied using a brush on the inner surface of the crown for one minute. Then resin cement (Breeze, Pentron Clinical Technologies, Wallingford, USA) was injected into the crowns which were then seated on the epoxy dies and the excess was removed. Each crown was light cured (Bluephase Ivoclar Vivadent, Schaan, Lichtenstein) from all aspects for 60 seconds.

\section{Fracture strength test}

Each IPS e.max Press crown cemented to its corresponding epoxy die was mounted in the lower fixed grip of the computer connected universal testing machine (Instron Universal testing machine model 3345, England). Each assembly was statically compressively loaded till fracture. The machine was operated at a crosshead speed of $1 \mathrm{~mm} / \mathrm{min}$. using a steel rod placed centrally at the occlusal surface of the crowns. The fracture of crowns was noticed when a crack was heard and a sudden drop in the load deflection curve occurred. The software of the machine recorded the force at which fracture occurred in Newton. Figure (1)

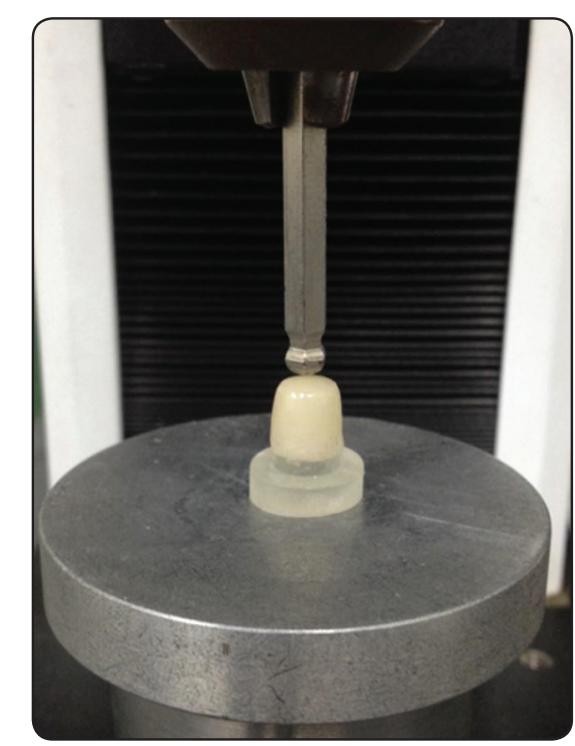

Fig (1): Crown cemented to epoxy die \& compressively loaded using an Instron machine

\section{Statistical Analysis test}

All data obtained in this research were calculated, tabulated and statistically analyzed using one-way ANOVA Test, then a Tukey Test was performed to determine significant differences between the tested classes using a confidence level of $0.05(\mathrm{p}<0.05)$.

\section{RESULTS}

\section{Marginal Gap:}

Means and standard deviations of the marginal gap of the tested groups are presented in table (1) and in figure (2), also stereomicroscope photographs showing marginal gaps for the tested groups, figure (3). One-way ANOVA Test was performed to determine the significant differences between the tested groups $(\mathrm{P}>0.05)$. The Tukey test for multiple comparisons of means at $(\mathrm{P}>0.05)$ was carried out following the one-way analysis of variance. Group 1 (100\% new) recorded the least marginal gap (32.7 $\mu \mathrm{m})$, while group 5 (100\% repressed) recorded the highest marginal gap $(120.91 \mu \mathrm{m})$. The statistical tests showed that there is no statistical significant difference between marginal gap of the first three groups $(100 \%$ new, $75 \%$ new $+25 \%$ repressed, $50 \%$ new $+50 \%$ repressed). On the other hand, there 
was a significant difference between these 3 tested groups and group 4 (25\% new $+75 \%$ repressed) . There was also a significant difference between group 4 and group 5 (100\% repressed).

TABLE (1) Means and Standard deviations of the marginal gap in microns $(\mu \mathrm{m})$ of the tested groups.

\begin{tabular}{|c|c|c|c|c|c|}
\hline Groups & $\begin{array}{c}\text { I } \\
100 \% \\
\text { new }\end{array}$ & $\begin{array}{c}\text { II } \\
75 \% \text { new } \\
+25 \% \\
\text { repressed }\end{array}$ & $\begin{array}{c}\text { III } \\
50 \% \text { new } \\
+50 \% \\
\text { repressed }\end{array}$ & $\begin{array}{c}\text { IV } \\
25 \% \text { new } \\
+75 \% \\
\text { repressed }\end{array}$ & $\begin{array}{c}\text { V } \\
100 \% \\
\text { repressed }\end{array}$ \\
\hline Means & $32.7^{\mathrm{a}}$ & $34.53^{\mathrm{a}}$ & $38.29^{\mathrm{a}}$ & $61.64^{\mathrm{b}}$ & $120.91^{\mathrm{c}}$ \\
\hline S.D. & 2.85 & 4.37 & 4.53 & 9.45 & 8.21 \\
\hline
\end{tabular}

\section{*Different letters denote significant difference}
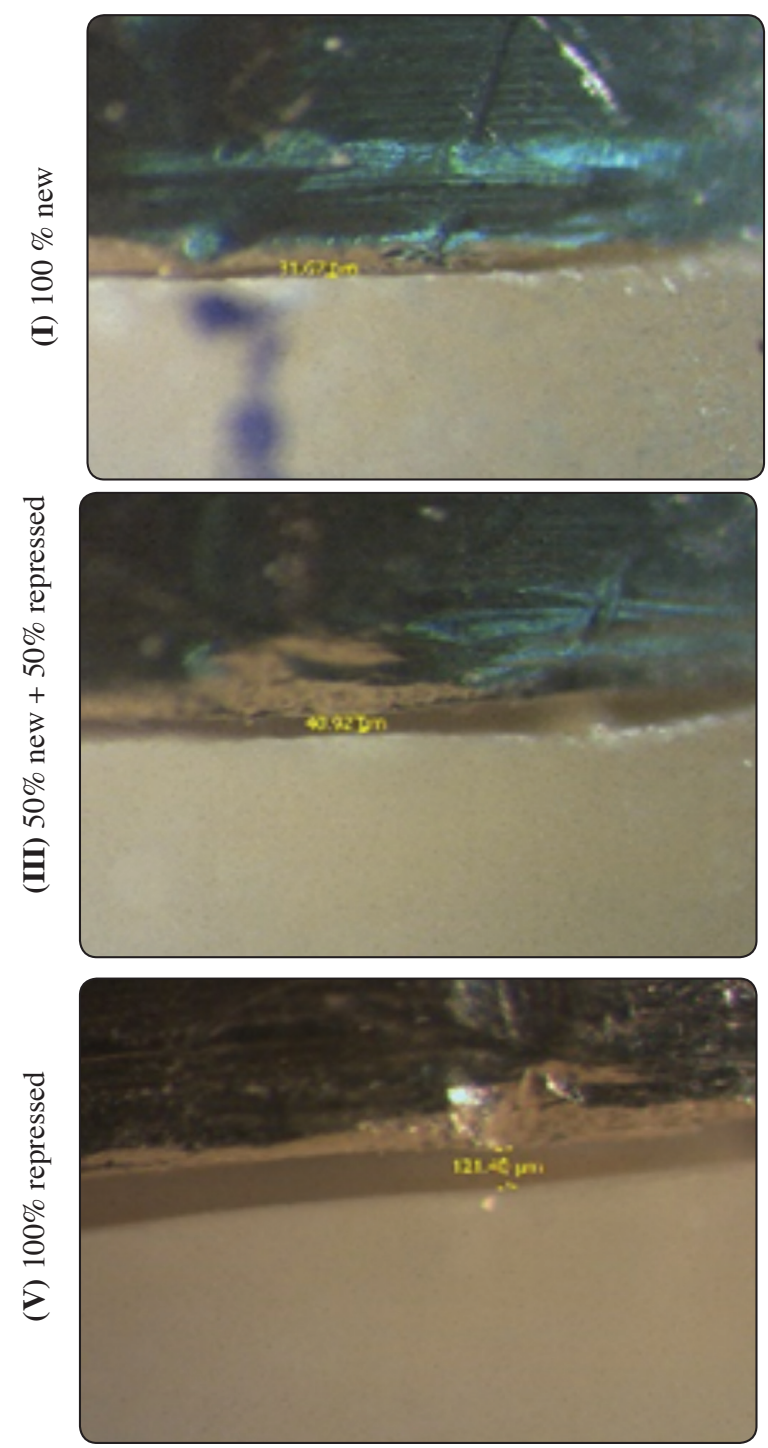

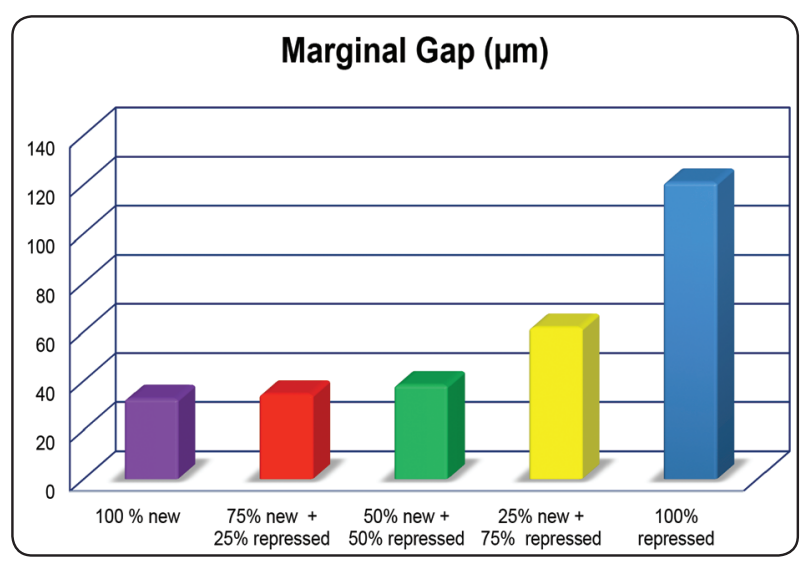

Fig (2) Comparison between the marginal gap of the tested groups

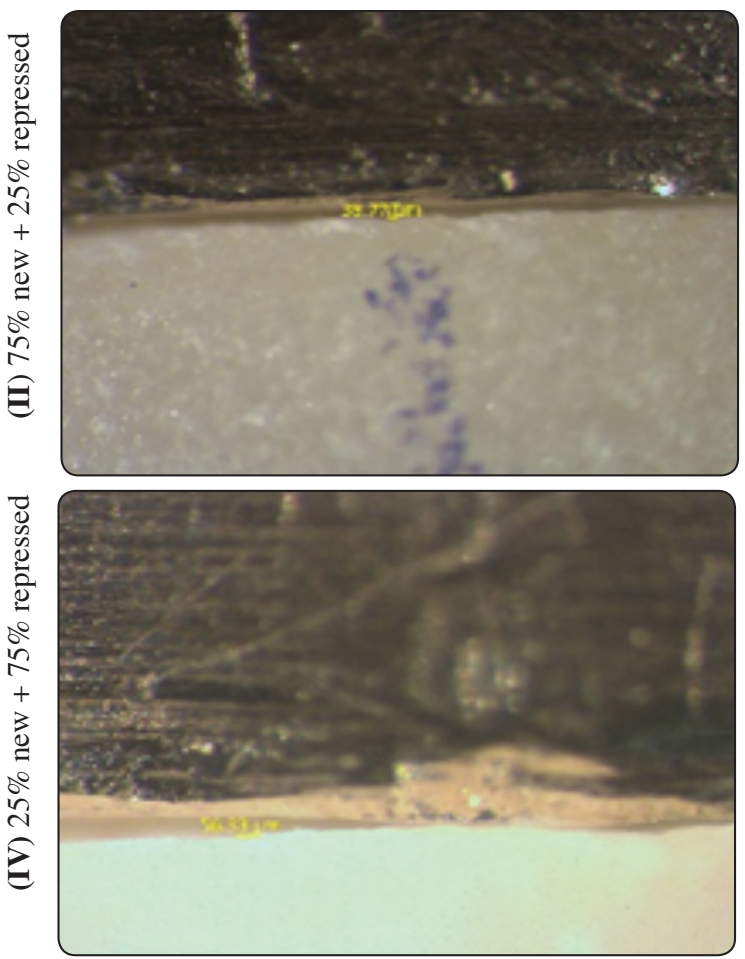

Fig (3): Stereomicroscope photographs showing marginal gaps for the tested groups. 


\section{Fracture strength:}

Means and standard deviations of fracture strength of the tested groups are presented in table (2) and figure (4). A one-way ANOVA Test was performed to determine the significant differences between the tested groups $(\mathrm{P}>0.05)$. The Tukey test for multiple comparisons of means at $(\mathrm{P}>0.05)$ was carried out following the one-way analysis of variance. Group I (100\% new) recorded the highest fracture strength $(929.724 \mathrm{~N})$, while group III (50\% new) recorded the least fracture strength $(819.366 \mathrm{~N})$. The statistical tests showed that there is a statistical significant difference between the first four groups and a siginficant difference between GroupV (100\% repressed) and Group I,II,III. While, there was no significant difference between Group IV and Group V.

TABLE (2) Means and Standard deviations of the fracture strength in newton $(\mathrm{N})$ of the tested groups.

\begin{tabular}{|c|c|c|c|c|c|}
\hline Groups & $\begin{array}{c}\text { I } \\
100 \% \\
\text { new }\end{array}$ & $\begin{array}{c}\text { II } \\
75 \% \text { new } \\
+25 \% \\
\text { repressed }\end{array}$ & $\begin{array}{c}\text { III } \\
50 \% \text { new } \\
+50 \% \\
\text { repressed }\end{array}$ & $\begin{array}{c}\text { IV } \\
25 \% \text { new } \\
+75 \% \\
\text { repressed }\end{array}$ & $\begin{array}{c}\text { V } \\
100 \% \\
\text { repressed }\end{array}$ \\
\hline Means & $929.724^{\mathrm{a}}$ & $909.476^{\mathrm{b}}$ & $819.36^{6} \mathrm{c}$ & $843.362^{\mathrm{d}}$ & $861.264^{\mathrm{d}}$ \\
\hline S.D. & 21.38 & 19.407 & 19.979 & 15.115 & 18.34 \\
\hline
\end{tabular}

*Different letters denotes significant difference

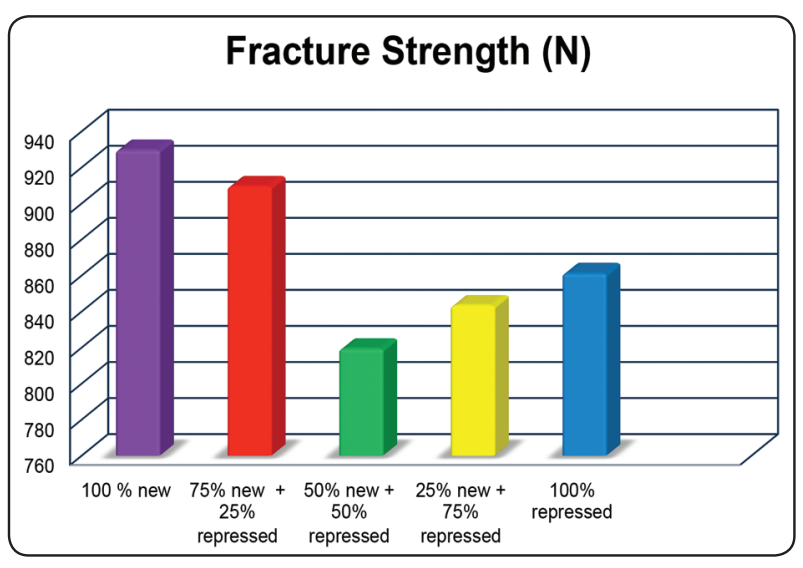

Fig (4) : Comparison between the fracture strength of the tested groups

\section{DISCUSSION}

For standardization the metal die was prepared using an industrial lathe machine. A notch was prepared on the occlusal surface of the die to ensure proper crown seating and to act as an anti-rotational feature. A heavy chamfer finish line $1.0 \mathrm{~mm}$ was prepared. Although, heavy chamfer and rounded shoulder finish lines were recommended for allceramic crowns, ${ }^{(29-31)}$ yet it was proved that heavy chamfer results in lower marginal gap compared to $90^{\circ}$ shoulder Al-Zubaidi and Al-Shamma (2015). (28) This was attributed to the less preparation depth and the more round angle between the axial and gingival seat of chamfer finish line. This enables more accurate preparation scanning and crown seating. Therefore, $90^{\circ}$ shoulder with slight round angle may cause improper crown seating and larger the vertical marginal gap. ${ }^{(32-34)}$

Fabrication of an accurate pattern is a critical step. It highly affects all-ceramic restorations, marginal fit. In this research, the metallic die was scanned, and resin patterns using a computerized numerical control (CNC) machine were built up layer-by layer. Resin possess strength, rigidity, and dimensional stability if immediate investment is not possible. ${ }^{(35)}$ Additive CAD/CAM technology was shown to fabricate accurate, uniform and standardized patterns. It reduces errors that may be encountered in the multistep conventional wax technique. After light polymerization of the new light polymerized modelling resins, high precision and stability are attained. ${ }^{(36-38)}$ Saleh $\mathbf{O}$ et al(2016), ${ }^{(37)}$ reported that the 3D printed patterns offered better marginal fit of IPS e.max Press crowns. They also recorded improved internal adaptation that consequently improved the fracture resistance of the crowns

In this study, marginal adaptation was evaluated using a stereomicroscope. It is a simple and convenient method as stated by Elrashid et al (2019). ${ }^{(39)}$ Measuring the marginal gap on the metallic die, that represent the prepared tooth was performed to simulate the clinical condition. Measurements 
were taken without cementation to omit the relative impact of the cementation process on the marginal fit and to allow determination of the system's precision. ${ }^{(37,40)}$

In the current study, the resultant marginal gap mean values were found to be within the clinically acceptable range, while that of Group V was above this range by $0.9 \mu \mathrm{m}$. as denoted by Christensen (1966), ${ }^{(41)}$ who considered the clinically acceptable marginal gap range from 34 to $119 \mu \mathrm{m}$ for subgingival and 2 to $51 \mu \mathrm{m}$ for supragingival margins. Also, McLean and von Fraunhofer in (1971), ${ }^{(42)}$ proved that the maximum marginal gap of dental restorations should not exceed $120 \mu \mathrm{m}$ to be clinically accepted.

Advancements of dental ceramic materials and processing techniques improved the marginal fit and the strength of ceramic restorations.

The results of this study may be related to the detrimental effect of repressing on physical and mechanical properties as well as change in microstructure of IPS e.max Press as detected by Tang et al(2014) ${ }^{(43)}$. This may also explain the significantly better marginal gap in Groups II, III, III and IV in relation to group V (100\% old).

For testing facture strength, the ceramic crowns were cemented to epoxy dies. Epoxy has a low modulus of elasticity to simulate the modulus of elasticity of the normal teeth. Øilo et al (2013), $(44,45)$ described this by that the epoxy abutment is compressed during axial loading, causing slight abutment bulging that produces tension in the cemented crown cervical region. So fracture occurs at the cervical margin simulating the clinical fractures. They recommended this method to obtain clinically relevant fracture loads.

Recording the highest fracture strength mean value for Group I that contains $100 \%$ new ceramic material and lower mean values for the other 4 groups comes in agreement with Tang. et al (2014), (43) who found a significant decrease in density, strength, toughness and hardness as well as increase in porosity of IPS e.max Press after repeated heat pressing. They attributed these results to the sparser distribution of lithium disilicate crystals detected by SEM after re-pressing that may cause easier intergranular crack propagation through the residual glass matrix, causing a lower fracture strength. Therefore, they concluded that repeated heat pressing renders the ceramic unfavourable for clinical use.

However these results contradicts Albakry et al(2004), ${ }^{(2,14,46)}$ who performed three researches to investigate the effect of reusing pressable ceramics. They studied the re-pressing of IPS Empress 2 and recorded insignificant decrease in the biaxial flexural strength of the re-pressed groups compared to the pressed ones. They attributed this to that pressing of the softened glass ceramic results in densification. They found increase in lithium disilicate crystals size due to pressing and repressing. They recorded a linear correlation between pressing total duration and crystals length. They concluded that pressing and repressing enhanced better crystal distribution which increased the flexure strength but not fracture toughness. They concluded that re-pressing the ceramic material did not result in significantly lower mechanical properties.

Gorman et al (2014), ${ }^{(47)}$ studied the reuse of IPS e.max Press, to predict the maximum number of pressing on biaxial flexure strength, Vickers hardness and fracture toughness of lithium disilicate as well as on microstructure using X-ray diffraction and scanning electron microscope. Although they found a slight decrease in strength with increased number of pressings yet, they found it insignificant and recorded no significant variation in material mechanical properties with subsequent pressings.

Also, these results contradict what was stated by Chung KH et al (2009), ${ }^{(17)}$ who investigated the effect of repeated heat pressing on biaxial flexure strength and microstructure of Empress 2. They found that re-pressed groups had higher mean strength value than the pressed group. They related 
this to that after repressing an interlocking, densely packed microstructure was formed with larger lithium disilicate crystal with preferred orientation. They recommended reusing ceramic residual materials for single time in some dental laboratories.

Also, El-Etreby A.S. and Ghanem L (2017), ${ }^{(48)}$ recorded the safety of using IPS e.max Press leftover pressed buttons regarding surface roughness and biaxial flexural strength.

However, comparing the results of the current study with other studies has the limitation that most of them studied the repressing of IPS Empress 2 not IPS e.max Press which differs in crystals size and percentage. Also, they used specimens in the form of discs which surely affected crystal alignment, where lithium disilicate crystals arrangement depends on the specimen configuration. In disks the crystals are randomly oriented at the surface plane. ${ }^{(49,50)}$ Heat pressing allows crystal alignment along the pressing direction, due to the high crystal ratio. When molten ceramic enters the specimen cavity through the sprue, its flow is constrained by the limited thickness and spreads radially to fill it. This alignment promotes higher resistance to crack propagation in a direction perpendicular to the crystal alignment thus, improves mechanical properties..$^{(46,51)}$

As for mixing new with old ceramics in different percentages, this is an innovative idea. No reference studies were found to compare the obtained results with, whether the fracture strength or the marginal gap. The increase of the marginal gap as the percentage of repressed ceramic increases as well as the significant decrease in fracture strength mean value in Groups II, III IV and V compared to Group I, having the lowest mean value in Group III(50\% new $/ 50 \%$ old) comes in agreement with Gorman et al (2014), ${ }^{(47)}$ who concluded that IPS e.max Press optimum properties are only obtained with the first pressing, Homogenous crystallization of interlocked needle like crystals leads to higher strength. This may justify that the fracture strength of Groups II (75\% new) and Group III (50\% new) were less than Group I, while Group IV(75\% old) although it had lower fracture strength than Group I yet, it showed higher fracture strength than Group III, which recoded the lowest mean value; as the degree of homogeneity is (50\%new 50\%old). Also, this explains the insignificant difference between Group IV \& V where Group V has higher strength than Group IV.

Based on the obtained results, the hypothesis for repressing ceramic was accepted as regard both marginal gap and fracture strength, as $100 \%$ repressed ceramic showed higher marginal gap and lower fracture strength than $100 \%$ new ceramic ingots. As regarding the effect of different mixing percentage, the hypothesis was partially accepted.

\section{CONCLUSIONS}

It was found within the limitations of this study:

1. Various weight percentages of repressed ceramics affected the marginal gap and had a significant effect when it exceeded $50 \%$, although all tested groups were clinically accepted.

2. Homogeneity of the ceramic structure had a positive effect on fracture strength, as the least fracture strength was recorded for the $50 \%$ new $+50 \%$ repressed ceramic group and it increased significantly as this relation increased towards either the new ingot ceramics or the repressed ceramic:

\section{REFERENCES}

1. Griggs J. Recent in material for all ceramic restorations. Dent Clin North Am. 2007;51(3):713- 727.

2. Albakry M, Guazzato M, Swain MV. Biaxial flexural strength and microstructure changes of two recycled pressable glass ceramics. J Prosthodont. 2004; 13:141-149.

3. Fernandes H R, Tulyaganov D U, Goel A Ribeiro M J Pascual M J, Ferreira J M F. Effect of $\mathrm{Al}_{2} \mathrm{O}_{3}$ and $\mathrm{K}_{2} \mathrm{O}$ content on structure, properties and devitrification of glasses in the $\mathrm{Li}_{2} \mathrm{O}-\mathrm{SiO}_{2}$ system. J. Eur.Ceram. 2010; 30: 2017-2030. 
4. Kim M J, Oh S H, Kim, J H, Ju S W, Seo, D G, Jun S H., Ahn J S, Ryu J J, Wear evaluation of the human enamel opposing different Y-TZP dental ceramics and other porcelains. J. Dent. 2012; 40: 979-988.

5. Tang X., Nakamura T, Usami, H., Wakabayashi K, Yatani H. Effects of multiple firings on the mechanical properties and microstructure of veneering ceramics for zirconia frameworks. J. Dent. 2012a; 40: 372-380.

6. Tang X., Tan Z, Nakamura T, Yatani H. Effects of ageing on surface textures of veneering ceramics for zirconia frameworks. J. Dent. 2012b; 40: 913-920.

7. Yuan K, Wang F, Gao J, Sun, X, Deng Z, Wang H, Chen J. Effect of sintering time on the microstructure, flexural strength and translucency of lithium disilicate glass- ceramics. J. Non-Cryst. Solids. 2013; 362: 7-13.

8. Zhang Y, Lee J J, Srikanth R, Lawn B R. Edge chipping and flexural resistance of monolithic ceramics. Dent. Mater. 2013; 29: 1201-1208.

9. Akar GC, Pekkan G, Cal, E, Eskitaşçıŏ̆lu G, Özcan M. Effects of surface-finishing protocols on the roughness, color change, and translucency of different ceramic systems. J. Prosthet. Dent. 2014; 112(2):314-321.

10. Dong J K, Luthy H, Wohlwend A, Scharer P. Heat-pressed ceramics: technology and strength. Int $\mathrm{J}$ Prosthodont. 1992; 5:9-16.

11. Probster L, Geis-Gerstorfer J, Kirchner E, Kanjantra P. In vitro evaluation of a glass ceramic restorative material. J Oral Rehabil 1997; 24:636-645.

12. Scientific Documentation IPS Empress 2. 1998. Ivoclar Vivadent AG. Available from: http://www.ivoclarvivadent.

13. Scientific Documentation IPS e.max Press.2011. Ivoclar Vivadent AG. Available from: http://www.ivoclarvivadent.

14. Albakry M, Guazzato M, Swain MV. Fracture toughness and hardness evaluation of three pressable all-ceramic dental materials. Journal of dentistry. 2003;31(3):181-188.

15. Stappert C F J, Att W, Gerds T, Strub J R. Fracture resistance of different partial-coverage ceramic molar restorations: An in vitro investigation. J Am Dent Assoc. 2006;137(4):514-522.

16. Stanton K T. Effects of repeated processing on the strength and microstructure of a heat-pressed dental ceramic. J Prosthet Dent 2014; 112: 1370-1376.

17. Chung KH, Liao JH, Duh JG, Chan DC. The effects of repeated heat-pressing on properties of pressable glassceramics. J Oral Rehabil. 2009; 36:132-141.
18. Felton D A, Kanoy B E, Bayne S C, Wirthman G P. Effect of in vivo crown margin discrepancies on periodontal health. J Prosthet Dent 1991; 65:357-364.

19. Knoernschild K L, Campbell S D. Periodontal tissue responses after insertion of artificial crowns and fixed partial dentures. J Prosthet Dent 2000; 84:492-498.

20. Kokubo Y, Ohkubo C, Tsumita M, Miyashita A, Vult von Steyern P, Fukushima S. Clinical marginal and internal gaps of Procera AllCeram crowns. J Oral Rehabil 2005; 32:526-30.

21. Boening KW, Wolf BH, Schmidt AE, Kästner K, Walter MH. Clinical fit of Procera AllCeram crowns. J Prosthet Dent. 2000; 84:419-424.

22. May KB, Russell MM, Razzoog ME, Lang BR. Precision of fit: the Procera AllCeram crown. J Prosthet Dent 1998;80: 394-404.

23. Weaver JD, Johnson GH, Bales DJ. Marginal adaptation of castable ceramic crowns. J Prosthet Dent 1991; 66:747-753.

24. Behr M, Proff P, Kolbeck C, Langrieger S, Kunze J, Handel $\mathrm{G}$, Rosentritt M. The bond strength of the resin-to-zirconia interface using different bonding concepts. J Mech Behav Biomed Mater 2011; 4:2-8

25. Scherrer SS, De Rijk WG and Belser UC. Fracture resistance of human enamel and three all-ceramic crown systems on extracted teeth. Int J Prosthodont. 1996; 9:580-585.

26. Yoshinari M and Derand T. Fracture strength of all-ceramic crowns. Int. J. Prosthodont. 1994; 7: 329 - 338.

27. Guess P C, Kulis A, Witkowski S, Wolkewitz M, Zhang Y, Strub J R. Shear bond strengths between different zirconia cores and veneering ceramics and their susceptibility to thermocycling. Dent Mater 2008; 24(11):1556-1567.

28. Al-Zubaidi Z, Al-Shamma A M W. The Effect of Different Finishing Lines on the Marginal Fitness of Full Contour Zirconia and Glass Ceramic CAD/CAM Crowns (An invitro study). JDMT. 2015; 4 (3): 127-136.

29. Yeo IS, Yang JH, Lee JB. In vitro marginal fit of three allceramic crown systems. J Prosthet Dent. 2003; 90(5): 459464.

30. Quintas AF, Oliveira F, Bottino MA. Vertical marginal discrepancy of ceramic copings with different ceramic materials, finish lines, and luting agents: an in vitro evaluation. J Prosthet Dent. 2004; 92:250-257.

31. Naert I, Van der Donck A, Beckers L. Precision of fit and clinical evaluation of all-ceramic full restorations followed between 0.5 and 5 years. J Oral Rehabil. 2005; 32:51-57. 
32. Lombardas P, Carbunaru A, McAlarney M E, Toothaker R W. Dimensional accuracy of castings produced with ringless and metal ring investment systems. J Prosthet Dent. 2000;84(1):27-31.

33. Kyu-Bok, Charn-Woon, Kyo-Han and Tae-Yub. Marginal and internal fit of all-ceramic crowns fabricated with two different CAD/CAM systems. Dent Mater J. 2008; 27(3):422-426.

34. Park SH, Lee KB. A comparison of the fidelity between various cores fabricated with CAD/CAM system. J Kor Acad Prosthodont. 2008; 43(3): 269-278.

35. Silva NR, Witek L, Coelho PG, Thompson VP, Rekow ED, Smay J: Additive CAD/CAM process for dental prostheses. J Prosthodont 2011; 20(2): 93-96.

36. Rajagopal P, Chitre V, Aras MA, A comparison of the accuracy of patterns processed from an inlay casting wax, an autopolymerized resin and a light- cured resin pattern material. Indian J Dent Res 2012; 23:152-156.

37. Saleh O, Ami RA, Abdellatif MA. Effect of different pattern construction techniques on the marginal adaptation, internal fit and fracture resistance of IPS-emax press crowns. EDJ. 2016;(62): 1141:1152.

38. Gonzalo E, Suärez MJ, Serrano B, Lozano JF. A comparison of the marginal discrepancies of zirconium and metal ceramic fixed dental prostheses before and after cementation. J Prosthet Dent. 2009; 102:378-384.

39. Elrashid AH, AlKahtani AH, Alqahtani SJ, Alajmi NB, Alsultan FH. Stereomicroscopic evaluation of marginal fit of e.max Press and e.max Computer-Aided Design and Computer-Assisted Manufacturing lithium disilicate ceramic crowns: An In vitro Study. J Int Soc Prevent Communit Dent 2019; 9:178-184.

40. Groten M, Axmann D, Probster L, Weber H. Determination of the minimum number of marginal gap measurements required for practical in-vitro testing. J Prosthet Dent 2000; 83:40-49.
41. Christensen GJ. Marginal fit of gold inlay castings. J Prosthet Dent. 1966 Mar-Apr;16(2): 297-305.

42. McLean JW, von Fraunhofer JA. The estimation of cement film thickness by an in vivo technique. Br Dent J. 1971 Aug 3;131(3): 107-111.

43. Tang X, Tang C, Su H, Luo H. The effects of repeated heatpressing on the mechanical properties and microstructure of IPS e.max Press. J Mech Behav Biomad Mater. 2014; 40:390-396.

44. Øilo M, Gjerdet NR. Fractographic analysis of all-ceramic crowns: a study of 27 clinically-fractured crowns. Dent Mater 2013; 29: e78-e84.

45. Øilo M, Kvam k, Tibballs JE, Gjerdet NR. Clinically relevant fracture testing of all-ceramic crowns. Dent Mater 2013; 29: 815-823.

46. Albakry M, Guazzato M, Swain M V. Influence of Hot Pressing on the Microstructure and Fracture Toughness of Two Pressable Dental Glass-Ceramics. J Biomed Mater Rers Part B: Appl Biomater. 2004; 71B:99-107.

47. Gorman CM, Horgan K, Dollard RP, Stanton KT. Effects of repeated processing on the strength and microstructure of a heat-pressed dental ceramic. J Prosthet Dent. 2014 Dec;112(6):1370-1376

48. El-Etreby AS, Ghanem L. The effect of repeated heat-pressing on the biaxial flexural strength and surface roughness of lithium disilicate glass ceramics. EDJ. 2017; 63:53-60.

49. Guazzato M, Albakry M, Ringer SP, Swain MV. Strength, fracture toughness and microstructure of a selection of all-ceramic materials. Part I. Pressable and alumina glassinfiltrated ceramics. Dent Mater. 2004; 20(5):441-448.

50. Albakry M, Guazzato M, Swain MV. Biaxial flexural strength, elastic moduli, and x-ray diffraction characterization of three pressable all-ceramic materials. J Prosthet Dent. 2003; 89(4):374380.

51. Sakaguchi RL, Powes JM. Craig's restorative dental materials. Elsevier MOSBY. 2012; $13^{\text {th }}$. Ed. 